\title{
SAFE Class Guidance of Action Research in Teaching: Prevention of Secondary Student-to-Student Bullying
}

\author{
Huang, Yu-Ping \\ The National Sun Yat-sen University (NSYSU)
}

\begin{abstract}
The phenomena of Cyberbully occurs on teenagers, which affects not only upon their academic performance, family and colleagues' relationship, but also the victim post-bullying reaction physically and psychologically. The Anti-bully prevention is extremely significant to the campus safety. Thesis carries out Action Research employed to practical experience, inspect the specific class bully issue, specific student requirement, the angle of teacher positive discipline and preventive strategy. In order to decrease the chance of bully action and increase the student empathy, take action of SAFE Class Guidance Lesson Plan (SCGLP) efficiently more into class to assist students preclude bully issue, purpose to create a Class Positive Discipline, sublimate them to learn and growth. Through SCGLP, the major discovery are as follows: (1) Substantially increase student empathy and class cohesion. (2) Efficiently Improve class positive and friendly discipline efficiently. (3) Efficiently decrease the occurrence of bully in class. (4) Invite the academic advisor as a cooperate partner, improve the efficiency and effects of research project.
\end{abstract}

Keyword: Anti-bully, Bullying prevention, Cyberbullying, Conflict resolution, Positive discipline 